Working Papers of the Institute of Empirical Economic Research

\title{
On Optimal Currency Areas and Common Cycles: Are the Acceding Countries Ready to Join the Euro?
}

Louisa Grimm

Sven Steinkamp

Frank Westermann

Working Paper No. 120

November 2020

Osnabrueck University

Institute of Empirical Economic Research

Rolandstr. 8 · 49069 0snabrück · Germany

School of Business Administration and 


\title{
On Optimal Currency Areas and Common Cycles: Are the Acceding Countries Ready to Join the Euro?
}

\author{
By Louisa Grimm, Sven Steinkamp ${ }^{1}$ and Frank Westermann \\ Osnabrück University \\ Institute of Empirical Economic Research \\ Rolandstr. 8, Osnabrück, Germany
}

November 2020

The former EU president Jean-Claude Junker has proposed that all countries of the European Union should also adopt the euro as their currency and recent research has shown that countries currently pursuing this goal indeed fulfill the classical Optimal Currency Area (OCA) criterion of positively correlated shocks with the European Monetary Union (EMU). We illustrate, however, that not only the correlation of shocks but also a common impulse response pattern over time is needed for a currency area to be optimal. We test this additional OCA criterion using the concept of a common serial correlation test. The test clearly rejects the notion that the potentially acceding countries share a common cyclical response pattern with the EMU aggregate - except for Sweden. Instead, the business cycles in most of the other countries exhibit only a very weak form of codependence.

Keywords: Codependent Business Cycles, Serial Correlation Common Feature, European Monetary Integration, Seasonality, Optimum Currency Area.

JEL Codes: C32; E32, F36.

Acknowledgments: We would like to thank Jules Leichter for helpful comments and suggestions and the Bundesbank's Regional office in Bremen, Lower Saxony and Saxony-Anhalt, as well as the Sievert-Foundation for financial Support.

${ }^{1}$ Corresponding author. E-Mail: sven.steinkamp@uni-osnabrueck.de 


\section{Introduction}

Twenty years after the introduction of the euro, there is a renewed interest in the topic of optimal currency areas, as the monetary union keeps expanding and three potential new member countries have recently expressed their interest in EMU membership. In a recent empirical assessment, Deskar-Škrbić et al. (2021) argue that the candidate countries are indeed ready to join the common currency, using an advanced version of the classical empirical method initially proposed by Bayoumi and Eichengreen’s classical 1993 article. ${ }^{2}$ In this paper, we take a fresh look at the evidence arguing that the empirical approach neglects a key feature of macroeconomic data, which is the persistence and often complex serial correlation patterns of shocks. Taking these into account, we find much more limited evidence of an Optimal Currency Area for most of the acceding candidate countries.

The basic idea of Bayoumi and Eichengreen (1993) was to take a trend-cycle decomposition and analyze the correlation of short-term shocks, which are interpreted as demand shock. The intuition for this approach follows from Mundell's (1961) work on optimum currency areas and it has more recently been formally illustrated by Berger et al. (2001). However, it is only the contemporaneous correlation which is considered and not the potential spillover of the shock to the next period, the one thereafter, and so on. The shocks are essentially assumed to be white noise processes, without any autoregressive element.

In a parallel strand of the literature started by Beine, Candelon, and Hecq (2000) and summarized in De Haan et al. (2008), the dynamics of the shock are exactly in the focus on the analysis. They use the serial correlation common feature test, initially developed by Engle and Kozicki (1993) and later extended by Vahid and Engle (1993, 1997), to analyze whether the impulse response patterns to external shocks are similar across countries. Like the initial paper by Bayoumi and Eichengreen, their assessment is rather negative and they reach ultimately the same conclusion on the set of countries that have started the EMU in the year 2001.

Our contribution to this literature is twofold. First, we document formally, following the theoretical setup of Berger et al. (2001), that a common persistence of shocks - and not only their contemporaneous correlation - is a necessary precondition for minimizing the costs associated with adopting a common currency. Postulating this new criterion, we provide an extension of the Mundel (1961) analytical framework and document that the studies relying on the serial correlation common feature test are indeed applying an appropriate testing

\footnotetext{
${ }^{2}$ This adds to the older meta-study by Fidrmuca and Korhonen (2006), indicating that central and eastern European countries exhibit a comparably high correlation with the euro area business cycle.
} 
procedure. ${ }^{3}$ Furthermore, we show that the initial assessment for the acceding countries of the EMU, by Deskar-Škrbić et al. (2021), may have been overly optimistic. For the potential new member countries, just as the earlier literature has documented for the initial twelve euro countries (EA12), there is hardly any evidence of a common impulse response pattern after an initial shock.

In developing our conceptual framework we take a simple version of the Barro-Gordon (1983) model, where, in the absence of persistence, the optimal regime choice depends on the correlation of domestic and foreign shocks - the typical criterion used in the earlier empirical literature. We add the feature that the common shocks can be autocorrelated and derive some additional results. First, we highlight that there exists an additional inflation bias that is independent of the well-known time-inconsistency bias. It can be positive or negative, depending on the relative persistence of the home and domestic shocks. The overall welfare, in an unconditional equilibrium, however, does not depend on the autocorrelation under flexible exchange rates.

The main findings concerning the persistence of shock are driven in the fixed exchange rate/monetary union case. We show in the model section that there exists an additional welfare loss from joining a monetary union - either for the existing union or for the joining country - if the persistence of shocks differs between the domestic and the foreign shock. The welfare loss is zero if, and only if, the persistence is identical. The implication is that in a symmetric equilibrium, a common persistence of shocks is indeed a new criterion for an optimum currency area. $^{4}$

An autoregressive process of order one, which we use to illustrate our point in the model, of course, does not fully capture the empirical autocorrelation functions observed in practice. Most quarterly GDP time series are autoregressive processes of orders between four to eight periods, often with alternating positive and negative autoregressive coefficients, which are responsible for a hump-shaped cumulative impulse response pattern. Therefore, we document that for higher-order autoregressive processes, a common set of AR parameters is needed. This similarity of autoregressive parameters is in the focus of the serial correlation common feature test of Beine et al. (2000) and others. The common serial correlation feature indeed ensures that the additional welfare loss from joining the monetary union is zero. Our model can be viewed as the theoretical underpinning of this testing approach, which is highly relevant for the OCA

\footnotetext{
${ }^{3}$ For instance, Beine and Hecq (2000), Candelon et al. (2005), Hecq et al. (2006), Sato and Zhang (2006), Cubadda et al. (2013), and Trenkler and Weber (2020).

${ }^{4}$ The problem of diverging effects to otherwise common shocks in currency areas has also been noted in the influential “one money, one market” report by the European Commission (1990).
} 
literature.

Coming back to the policy question of the acceding countries decision to join the EMU, we take the model to the data by estimating serial correlation common feature (SCCF) tests for all potential candidates, i.e. Bulgaria, the Czech Republic, Croatia, Hungary, Poland, Romania, and Sweden (SWE). In a preliminary exercise, eyeballing the autocorrelation functions of each country compared to that of the EA12-countries provides a first impression of similarities and differences. While some countries have unique patterns, others look quite close and a more formal test is warranted.

We then document the trend and seasonality properties of the data, before estimating two versions of the SCCF-test based on Cubadda (2001), who proposed an integrated approach of estimating common serial correlation, common trends, and seasonality. The tests are conducted using a two-stage least squares and a GMM estimator. The robustness of the results is verified using the older Tiao and Tsay (1989) test, as well as an analysis of the optimal lag choice, which often critically affects the common features test results.

Overall, the evidence for common cyclical response patterns to exogenous shock is very limited when considering the strict form of the SCCF-test, which implies perfect collinearity between the impulse response patterns. Among the countries analyzed, Sweden comes closest to forming an Optimal Currency Area with the current EMU countries. Using the Cubadda (2001) approach, we indeed cannot reject the null hypothesis of a common cycle in our benchmark regression. One should be cautious about this finding, however, as in the Tiao and the Tsay (1989) robustness test, we fail to reject the null in even the case of Sweden.

For Croatia, Hungary, and the Czech Republic, we do find common cyclical elements when considering the less strict version of the codependence, which allows for an initially asymmetric response in the first quarter, but the common reaction thereafter. Together with the EA12, they form a codependent cycle of order one, for at least one of the estimators used (2SLS or GMM). Finally, all countries show some higher-order codependence of order two or three, which, however, is hardly relevant in practice, given the overall short-lived cyclical nature of GDP shocks in quarterly data.

Overall, while we do no challenge the existence of largely common shocks during the past 20 years, as reported in Deskar-Škrbić (2021), the analysis of asymmetric response patterns leads to a much more conservative assessment about the readiness of countries, and the possible size of a welfare loss, when joining the monetary union.

In Section 2, we present our conceptual model-framework. Section 3 illustrates how our main findings generalize to higher-order AR-processes and lead to the common serial 
correlation features test. Section 4 includes the preliminary tests, such as a visual inspection of the correlograms and the seasonal unit root and cointegrations properties. Section 5 reports the main findings on common cyclical features and the sensitivity analysis and Section 6 draws some conclusions.

\section{A conceptual framework}

To motivate the use of a serial correlation common feature test, we set up a very simple model in the classical Barro-Gordon (1983) framework. This model builds on Berger et al. (2001) who have analyzed the optimal exchange rate regime choice in the presence of contemporaneous country-specific shocks. The decision on the exchange rate regime in this model is based on the difference in expected losses in both regimes. Our contribution is to highlight the effects of autocorrelated shocks and to trace their effects on the inflation bias, output, and welfare.

First, we analyze the case of flexible exchange rates. We start with a stochastic version of the Lucas-supply schedule:

$$
y=\alpha\left(\pi-\pi^{e}\right)+\varepsilon_{t},
$$

where $y$ is output, $\pi$ the inflation rate and $\pi^{e}$ is expected inflation. $\varepsilon_{t}$ is an error term, which we assume to follow an $\operatorname{AR}(1)$ process, $\varepsilon_{t}=\gamma \varepsilon_{t-1}+v_{t} \cdot v_{t}$ is a white noise shock, and $\gamma$ measures the degree of persistence of the shock. We assume $0<\gamma<1$, i.e. $\varepsilon_{t}$ is positively autocorrelated but the stochastic process is stationary. The central bank minimizes the following loss function:

$$
L_{\text {flex }}=E\left[\lambda\left(\alpha\left(\pi-\pi^{e}\right)+\gamma \varepsilon_{t-1}+v_{t}-y^{*}\right)+\pi^{2}\right]
$$

subject to the inflation rate. ${ }^{5}$ Foreign variables are denoted For simplicity, we assume that the central bank can control the inflation rate directly. The time-structure of the model is a follows: $\alpha, \lambda$, as well as foreign inflation and output, $\pi^{*}, y^{*}$, are predetermined. At the beginning of the period, workers form inflation expectations. The central bank than chooses the optimal inflation rate after observing the shock $v_{t}$, which has zero mean and a variance of $\sigma_{v}^{2}$. Thereafter $y$ and $L$ follow from the Philipscurve based on $\pi$ and $\pi^{e}$. Equilibrium values for $\pi$ and $y$ are then given by:

$$
\pi=\alpha \lambda\left(y^{*}-\varepsilon_{t-1} \gamma\right)-\frac{\alpha \lambda}{\left(1+\alpha^{2} \lambda\right)} v_{t} \quad \text { and } \quad y=\gamma \varepsilon+\frac{1}{1+\alpha^{2} \lambda} v_{t}
$$

\footnotetext{
${ }^{5}$ A micro-founded justification for the reduced-form relations in the Barro-Gordon model is derived in Reis (2003).
} 
These expressions simplify to the familiar expressions in the literature when setting the persistence parameter $\gamma$ equal to zero.

Lemma 1. The persistence of shocks affects the inflation bias.

Proof. $E_{t}[\pi]^{\gamma \neq 0}=\alpha \lambda\left(y^{*}-\varepsilon_{t-1} \gamma\right) \cdot E_{t}[\pi]^{\gamma \neq 0}-E_{t}[\pi]^{\gamma=0}=-\varepsilon_{t-1} \alpha \lambda \gamma$.

Depending on the sign of the shock in the previous period, this effect can either strengthen or reduce the inflation bias. This preliminary result is known from Bleaney (2001), who derives the implications for inflation persistence, which is shown to depend on the degree of shocks' autocorrelation and the exchange rate regime.

More importantly in the context of our overall question on the impact of persistence on the optimal exchange rate regime choice is the following finding that can be derived by plugging the values for $\pi$ and $y$ into the loss function.

Lemma 2. The shock persistence does not affect expected losses in a flexible exchange rate case.

Proof. $L_{\text {flex }}^{\gamma>0}-L_{\text {flex }}^{\gamma=0}=-\lambda \gamma \varepsilon\left(\lambda \alpha^{2}+1\right)(2 y-\gamma \varepsilon)$ and $E\left[L_{\text {flex }}^{\gamma \neq 0}\right]-E\left[L_{\text {flex }}^{\gamma=0}\right]=0$.

It is important to keep in mind that while the government chooses the optimal inflation rate after observing the shock, the shock is still a stochastic variable when the exchange rate regime is decided upon. Therefore, its mean-zero characteristic needs to be taken into account when computing the expected aggregate welfare loss. Under flexible exchange rates, when a central bank can fully respond to positive and negative shocks, the autocorrelation does not constitute an additional welfare loss to the economy. ${ }^{6}$

Next, we consider the case of fixed exchange rates, or equivalently a country that joined a monetary union (permanently fixed exchange rates). We have the same autocorrelated output-function, $y=\alpha\left(\pi-\pi^{e}\right)+\varepsilon_{t}$ with $\varepsilon_{t}=\gamma \varepsilon_{t-1}+v_{t}$, but inflation, in this case, is determined by the purchasing power parity, which is given by

$$
\pi=\pi^{*}+\theta_{t}
$$

where $\theta_{t}$ is the shock from the foreign country, which we also assume to be autocorrelated:

$$
\theta_{t}=\delta \theta_{t-1}+u_{t},
$$

\footnotetext{
${ }^{6}$ That is, in our model, the additional welfare effect of the regime choice in the presence of shock persistence is caused by differences in the ability to conduct macroeconomic stabilization alone, and is not affected by the credibility of monetary policy. For recent research on the latter see, e.g., Chari et al. (2020) or Clerc et al. (2012).
} 
where $u_{t}$ is a white noise shock and $\delta$ captures the degree of persistence of shocks in the foreign country. The output of the home country is, therefore: $y=\alpha u_{t}+\gamma \varepsilon_{t-1}+v_{t}$. We can plug both expressions into the loss function:

$$
L_{f i x}=E\left[\lambda\left(\alpha u_{t}+\gamma \varepsilon_{t-1}+v_{t}-y^{*}\right)^{2}+\left(\pi^{*}+\delta \theta_{t-1}+u_{t}\right)^{2}\right]
$$

As the central bank has fixed its exchange rate and is importing the inflation rate from abroad, the inflation rate is no longer a choice parameter.

To focus on the asymmetric persistence and its implications for welfare and exchange rate regime choice, we now set $u=v$. That is, the stochastic elements of the time-series process are identical and any differences are only driven by the persistence parameters $\delta$ and $\gamma$. In the terminology of the OCA theory, this captures the case of symmetric shocks with asymmetric effects. ${ }^{7}$

Proposition 3. When joining a monetary union, there is an additional welfare gain/loss from asymmetric persistence.

Proof. $E\left[\begin{array}{c}\delta \neq \gamma \\ f i x\end{array}\right]-\mathrm{E}\left[L_{f i x}^{\delta=\gamma}\right]=\operatorname{VAR}\left(\theta_{t}\right)\left(\delta^{2}-\gamma^{2}\right)$, with $\operatorname{VAR}\left(\theta_{t}\right)=\frac{\sigma_{v}^{2}}{\left(1-\delta^{2}\right)}$. The expression is zero if, and only if, $\delta=\gamma$.

Note that the expression for the additional welfare effect can get negative if shocks are more persistent in the joining country than in the monetary union $(\gamma>\delta)$. That is, there is always an argument to anchor unilaterally against a stable country. It follows that common persistence in two countries forming a monetary union is a new criterion for optimal currency areas that so far has not been postulated formally in the literature.

Corollary 4. The only symmetric equilibrium where two countries find it optimal to form a monetary union is the when $\delta=\gamma$.

\section{From model to data}

The empirical implication from the conceptual framework discussed above is that the persistence of shocks in two countries forming a monetary union should be identical. A typical way to measure the persistence is looking at estimates of the half-lifes, which for the set of acceding countries to the EMU are reported in Figure 1 of the Appendix. This preliminary inspection of the data suggests that the countries may indeed form an Optimal Currency Area, as the persistence in the candidate countries is not statistically different from that of the

\footnotetext{
${ }^{7}$ Kohler (2002) shows how the presence of externalities and incentives to free-ride may create additional welfare costs for joining a monetary union even when shocks are symmetric.
} 
monetary union.

This simplified approach, however, has two shortcomings. First, the standard errors of half-life estimates are known to be large. Thus, it is hardly a reliable source of information. Secondly, it abstracts from the possibility of higher-order autoregressive processes, which are common in quarterly macroeconomic data. Most time-series’ on GDP typically display both a partial autocorrelation function that is significant for about four to six quarters, as well as a strong seasonal pattern.

When extending Proposition 3 to higher-order AR(p) processes of the same order for $\theta$ and $\varepsilon$, we get the following expression for the additional welfare loss under asymmetric persistence:

$$
\operatorname{VAR}\left(\theta_{t}\right) \sum_{p=1}^{P}\left(\delta_{p}^{2}-\gamma_{p}^{2}\right)+2 \operatorname{VAR}\left(\theta_{t}\right) \sum_{p=1}^{P-1} \sum_{q=p+1}^{P} \varphi_{q-p}\left(\delta_{p} \delta_{q}-\gamma_{p} \gamma_{q}\right)
$$

Thus, not only the persistence parameters of the AR(1)-term but all coefficients in the $\operatorname{AR}(\mathrm{p})$ process need to be identical for this expression to be zero, i..e $\left|\delta_{i}\right|=\left|\gamma_{i}\right|, \forall i$.

Intuitively, Eq. 3 can be interpreted as the expected squared deviation of the two processes. ${ }^{8}$

The empirical approach of a serial-correlation-common-feature test (SCCF), which was developed by Engle and Kozicki (1993) and that has been applied in the context of the OCA and business cycle synchronization literature ${ }^{9}$ thus indeed constitutes a model-consistent empirical approach to assess the existence of an Optimal Currency Area. It tests for common higher-order $\mathrm{AR}(\mathrm{p})$ process in different time series by identifying the existence of a linear combination of two variables that is free of autocorrelation. An alternative interpretation of the SCCF is that the impulse response patterns of two variables, when faced with a common exogenous shock, need to identical.

\footnotetext{
${ }^{8}$ There are two additional zero points: There is a naïve solution if the common shock has a zero variance. Further, the welfare loss becomes zero if the first summand of Eq. 3 is equal to the negative second summand. This, however, requires the AR-coefficients to be very distinct linear combinations of each other. For example, it requires $\gamma_{2}=\delta_{1} \gamma_{1}-\operatorname{SQRT}\left(\delta_{1}{ }^{2}\left(-\delta_{2}{ }^{2}+\gamma_{1}{ }^{2}+1\right)+\left(\delta_{2}-1\right)^{2}\left(\delta_{2}{ }^{2}-\right.\right.$ $\left.\left.\gamma_{1}^{2}\right)\right) /\left(\delta_{2}-1\right)$ in the $\operatorname{AR}(2)$-case. Intuitively, this situation arises if the expected deviations in different periods exactly offset each other, i.e. if the imported spillover at time $t$ equals the 're-export' of the same shock in later periods.

${ }^{9}$ See, e.g., Beine and Hecq (2000), Candelon et al. (2005), Hecq et al. (2006), Sato and Zhang (2006), Cubadda et al. (2013), and Trenkler and Weber (2020).
} 
Since the first proposal of the SCCF by Engle and Kozicki (1993) and Vahid and Engle $(1993,1997)$, there have been several advancements of the testing procedure that are relevant to our dataset. First, as shown by Cubadda (1999) the co-existence of seasonality and autocorrelation requires an integrated approach to modeling the data. The usage of de-seasonalized data may lead to an incorrect finding of common cycles. As all countries in our dataset indeed have a seasonal component, this point is particularly relevant for our analysis.

In the following empirical section, we first consider the long term trend-dynamics before finally conducting the common serial correlation test. We perform both, the strong form of the SCCF-test, as well as the less restrictive test for codependence, which was first discussed in Vahid and Engle (1997). ${ }^{10}$

\section{Preliminary Analysis}

The quarterly dataset was extracted from Eurostat and is displayed in Figure 2 in seasonal differences. Eyeballing the data we see immediately some commonalities across countries, such as the boom-period in the mid-2000s, the cyclical downturn after the global financial crisis in $2007 / 8$, as well as a rebound and a renewed recession after the beginning of the sovereign debt crisis in 2010 and again a rebound thereafter. ${ }^{11}$ Since roughly 2012 most countries have displayed a relatively steady growth path.

\section{FIGURE 2 HERE}

A standard response to an exogenous shock is then displayed in Figure 3. For each country, we show the correlograms that display the autocorrelation of each time series. It can be interpreted as the cyclical response pattern of each country to an exogenous shock. In this representation of the data, we already see that the response patterns can be quite different across countries - despite the similarities of the half-lifes reported in the previous section.

\section{FIGURE 3 HERE}

Each of the acceding countries in this figure is displayed together with the correlogram of the EA12 countries - the set of countries for which we have a consistent dataset of 83

\footnotetext{
${ }^{10}$ Although, the test for scalar components models of order $(0, q)$ by Tiao and Tsay (1989) can also be interpreted as the first consistent, but non-optimal, test for codependent cycles.

${ }^{11}$ Table 1 of the Appendix confirms that there is indeed a sizable degree of correlation between the seasonal growth rates of GDP.
} 
observations as full Eurozone members. ${ }^{12}$ The EA12 aggregate is characterized by a typical positive autocorrelation for about 4-5 quarters and a negative, but somewhat smaller, autocorrelation, for the 4-8 quarters thereafter. Thus, when accumulating this impulse response patterns in the GDP growth rates, one gets the typical up-and downswing patterns in the associated levels of GDP around its trend. Thereafter there are further up- and downs, which however are statistically insignificant (we omit the standard errors in this graph for a better visual illustration for commonalities and differences in the point estimates).

The correlograms of the acceding countries, by contrast, are quite different. Except for Poland and Sweden, most countries display a much longer positive autocorrelation and a delayed cyclical rebound. Cumulatively, this would imply a much longer cycle. While this first pass gives a visual impression of the data, a formal test on the colinearity of impulse response patterns needs to be conducted to precisely pin down which country may fulfill the OCA criterion postulated in the previous section and which countries do now.

An integral part of the analysis of common cycles is the consideration of trends and seasonal elements in the data. We, therefore, start the formal regression analysis by conducting the respective tests needed for the subsequent analysis of common cycles. Table 2 reports the seasonal unit root tests $\left(\mathrm{HEGY}^{13}\right)$, which shows that the time series of all countries are integrated at the zero frequency, a plausible finding as all data are in logged levels. At the frequency $\pi / 2$ all countries including the EA12 except Bulgaria and Croatia are stationary. The Czech Republic and Sweden are further stationary at frequency $\pi$.

\section{TABLE 2 HERE}

We take these stationarity properties into account when testing for cointegration in the next step. Table 3 shows that all countries except for Romania, Hungary, and the Czech Republic indeed are cointegrated, and thus share a common long-term trend with the EA12. Regarding the cointegration at frequency $\pi$, we find that Bulgaria and Poland also share a common stochastic seasonal trend with the EA12.

\section{TABLE 3 HERE}

While nor directly relevant for the OCA literature, it is very important to take account of these characteristics of the data when performing the common serial correlation test in the next section. We will - wherever necessary - include the error correction term in the list of

\footnotetext{
12 The EA12 consist of Austria, Belgium, Finland, France, Germany, Ireland, Italy, Luxembourg, Netherlands, Portugal, Spain, and Greece. Our results are not affected by this choice and also hold e.g. for the EA19 countries. This is not surprising given a correlation between the two series' of near unity. ${ }^{13}$ See Hylleberg et al. (1990).
} 
instruments when conducting the common features tests.

\section{Codependence and common cycles}

We now get to the main part of the analysis - the test for the existence of common cyclical patterns across countries, i.e. a common impulse pattern to an exogenous shock. The results are summarized in Table 4. There are in principle two different approaches to conduct a common serial correlation common feature test, one is regression-based and one is based on canonical correlation analysis, similar to the Engel-Granger two-step and the Johansen multivariate approach to the cointegration test. In our exercise, we take the latter approach and estimate the parameters with OLS as well as with GMM. ${ }^{14}$

\section{TABLE 4 HERE}

When starting with the strict form of identical impulse response patterns, we need to consider the first column of test statistics and associated p-values, labeled "codependence of order zero". This table illustrates that indeed most of the countries do not share an exactly common impulse response pattern, not even Poland, which after the first eyeballing the data have appeared to be quite similar to the EA12. The only country which indeed shares a common impulse response pattern appears to be Sweden.

A somewhat weaker definition of a common cycle could be used where the initial response (at lag 1) is allowed to be different, but all subsequent lags would be required to be identical. This is considered to be a codependent cycle of order one and may also be of relevance for the OCA case, although it does not follow directly from our model. When applying this less strict criterion, Table 4 shows that the Czech Republic and Hungary also display some similarity in the sense of a common, but not perfectly synchronized common cycle. Finally, when considering higher orders up to three, we find a common feature for all countries for at least one of the two testing procedures.

To further explore the robustness of the limited finding on a common seasonal pattern, we first consider the choice of lag length in the common features test. In our baseline specification, the lag length was determined by the Akaike Information Criterion (AIC). However, underspecification of the lag length might lead to an overly easy rejection of the null hypothesis of 'no common serial correlation feature' as any remaining autocorrelation in the residuals would be picked up in the second stage of the test. We therefore also explored other lag structures to illustrate this point. Table 5 shows the results when adding or dropping one lag,

\footnotetext{
${ }^{14}$ Note that at frequency zero, the 2S-GMM and 2SLS tests are equivalent.
} 
compared to the one indicated by the AIC. We indeed find that with shorter lag length, there is an even stronger rejection of the null hypothesis, while at a larger lag length, we cannot reject a common serial correlation feature for the case of the Czech Republic at the conventional 5\% significance level anymore, when using the 2SLS procedure that leads to a p-value of 0.068 . We nevertheless keep the AIC as our benchmark. This is because the alternative Schwarz Information Criterion indicates the same, or less lags to be included in the exercise. Also, when using the $10 \%$ level, the result of the Czech Republic would be negative, and the GMM test even rejects the common feature at $5 \%$.

\section{TABLE 5 HERE}

As another robustness check, Table 6 reports the results of the earlier canonical correlation-based version of the common features test of Tiao and Tsay (1989), of which the previously reported test can be seen as a generalization. Schleicher (2007) showed that the optimal GMM estimator tends to slightly under-reject and the Tiao and Tsay test tends to slightly over-reject at sample sizes comparable to those in our analysis. When using this test, however, we confirm most of the findings above, except for Sweden, which according to the strict common features test does not constitute an Optimal Currency Area with the EMU countries.

\section{TABLE 6 HERE}

All in all, the evidence of common persistence and the similarity of autoregressive coefficients between the EU12 and the acceding countries is very weak. The case of Sweden, for which we have conflicting results from different testing procedures, remains ambiguous.

\section{Conclusion}

Twenty years after the first group of twelve countries has started the European Monetary Union, its size has increased to currently 19 members. A further extension is an explicit goal of the European Union, most prominently articulated by its former president Jean-Claude Junker, who proposed the "Euro for all" agenda for the coming years. On the side of the potentially acceding countries, the attitude towards joining the EMU is mixed. While three candidate countries are pursuing a euro introduction in the foreseeable future, the others are more reluctant.

Whether or not an EMU membership is desirable crucially depends on the welfare loss that results from the loss of a country-specific monetary policy. While a large body of literature has already explored this topic, we highlight one aspect of the debate that so far has received 
only little attention. It is not only the correlation of shocks between the new member state and the present currency union but also the dynamic response pattern to the shock over time that matters. While previous research has shown that the potential candidate countries appear to fit well with regard to the correlation of shocks, we show that the impulse response patterns over time are quite different for most countries, i.e. there is evidence for an asymmetric response to common shocks.

The serial correlation common feature test has been used by a few authors in the context of the OCA literature already and comes to quite similar conclusions for the group of the early EMU members. Our paper may serve as a theoretical underpinning for the appropriateness of the earlier tests. The testing procedure developed by Engle and Kozicki (1993) and others, indeed is a model-consistent test of a newly postulated OCA criterion in this paper. In this sense, our paper may not only be relevant for the three countries currently deciding whether or not to join the EMU but more generally could serve as a guideline for currency unions or fixed exchange rate policies. In future research, for instance, the 15 countries that recently decided to form the West African Currency Union, and their potential extension to a full African Currency Union, may be relevant applications.

\section{References}

Barro, R. J., \& Gordon, D. B. (1983). Rules, discretion and reputation in a model of monetary policy. Journal of monetary economics, 12(1), 101-121. https://doi.org/10.1016/0304-3932(83)90051-X

Bayoumi, T., \& Eichengreen, B. (1993). Shocking Aspects of European Monetary Unification. In: Torres, F., \& Giavazzi, F. (Eds). Adjustment and Growth in the European Monetary Union, Cambridge University 193-229. https://doi.org/10.1017/CBO9780511599231.014

Beine, M., Candelon, B., \& Hecq, A. (2000). Assessing a perfect European optimum currency area: a common cycles approach. Empirica, 27(2), 115-132. https://doi.org/10.1023/A:1026516026943

Bleaney, M. (2000). Exchange rate regimes and inflation persistence. IMF Staff papers, 47(3), 387-402. https://doi.org/10.2307/3867654

Candelon, B., Hecq, A., \& Verschoor, W. F. (2005). Measuring common cyclical features during financial turmoil: Evidence of interdependence not contagion. Journal of International Money and Finance, 24(8), 1317-1334. https://doi.org/10.1016/j.jimonfin.2005.08.011

Chari, V. V., Dovis, A., \& Kehoe, P. J. (2020). Rethinking optimal currency areas. Journal of Monetary Economics, 111, 80-94. https://doi.org/10.1016/j.jmoneco.2019.01.023

Clerc, L., Dellas, H., \& Loisel, O. (2011). To be or not to be in monetary union: A synthesis. Journal of International Economics, 83(2), 154-167. https://doi.org/10.1016/j.jinteco. 2010.11.002

Cubadda, G. (1999). Common cycles in seasonal non-stationary time series. Journal of Applied Econometrics, 14(3), 273-291. https://doi.org/10.1002/(SICI)1099-1255(199905/06)14:3 \%3C273::AID-JAE498\%3E3.0.CO;2-N 
Cubadda, G., \& Hecq, A. (2011). Testing for common autocorrelation in data-rich environments. Journal of Forecasting, 30(3), 325-335. https://doi.org/10.1002/for.1186

Cubadda, G., Guardabascio, B., \& Hecq, A. (2013). Building a Synchronous Common-Cycle Index for the European Union. In: Cheung, Y. W., \& Westermann, F. (Eds.). Global interdependence, decoupling, and recoupling. MIT Press, pp. 37-54. https://doi.org/10.7551/mitpress/9780262019804.001.0001

De Haan, J., Inklaar, R., \& Jong-A-Pin, R. (2008). Will business cycles in the euro area converge? A critical survey of empirical research. Journal of economic surveys, 22(2), 234-273. https://doi.org/10.1111/j.1467-6419.2007.00529.x

Deskar-Škrbić, M., Kotarac, K., \& Kunovac, D. (2021). The third round of euro area enlargement: Are the candidates ready? Journal of International Money and Finance, 107, 102205. https://doi.org/10.1016/j.jimonfin.2020.102205

Engle, R. F., \& Kozicki, S. (1993). Testing for common features. Journal of Business \& Economic Statistics, 11(4), 369-380. https://doi.org/10.2307/1391623

European Commission (1990). One Market, One Money - An Evaluation of the Potential Benefits and Costs of Forming an Economic and Monetary Union. European Economy 44.

Fidrmuc, J., \& Korhonen, I. (2006). Meta-analysis of the business cycle correlation between the euro area and the CEECs. Journal of Comparative Economics, 34(3), 518-537.

Hecq, A., Palm, F. C., \& Urbain, J. P. (2006). Common cyclical features analysis in VAR models with cointegration. Journal of Econometrics, 132(1), 117-141. https://doi.org/10.1016/j.jeconom.2005.01.025

Hylleberg, S., Engle, R. F., Granger, C. W., \& Yoo, B. S. (1990). Seasonal integration and

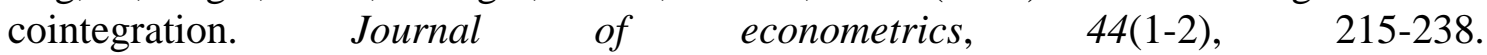
https://doi.org/10.1016/0304-4076(90)90080-D

Kohler, M. (2002). Coalition formation in international monetary policy games. Journal of International Economics, 56(2), 371-385. https://doi.org/10.1016/S0022-1996(01) 00128-3

Mundell, R. A. (1961). A theory of optimum currency areas. American Economic Review, 51(4), 657-665.

Reis, R. (2003). Where is the natural rate? Rational policy mistakes and persistent deviations of inflation from target. The B.E. Journal of Macroeconomics, 3(1). https://doi.org/10.2202/1534-6013.1118

Sato, K., \& Zhang, Z. (2006). Real Output Co-movements in East Asia: Any Evidence for a Monetary Union? World Economy, 29(12), 1671-1689. https://doi.org/10.1111/j.1467-9701.2006.00863.x

Schleicher, C. (2007). Codependence in cointegrated autoregressive models. Journal of Applied Econometrics, 22(1), 137-159. https://doi.org/10.1002/jae.930

Tiao, G. C., \& Tsay, R. S. (1989). Model specification in multivariate time series. Journal of the Royal Statistical Society: Series B (Methodological), 51(2), 157-195. https://doi.org/10.1111/j.2517-6161.1989.tb01756.x

Trenkler, C., \& Weber, E. (2020). Identifying shocks to business cycles with asynchronous propagation. Empirical Economics, 58(4), 1815-1836. https://doi.org/10.1007/s00181-018-1563-z

Vahid, F., \& Engle, R. F. (1993). Common trends and common cycles. Journal of Applied Econometrics, 341-360.

Vahid, F., \& Engle, R. F. (1997). Codependent cycles. Journal of Econometrics, 80(2), 199-221. https://doi.org/10.1016/S0304-4076(97)00032-8 
Figure 2: Graphical Analysis of (Seasonal) Real GDP Growth Rates
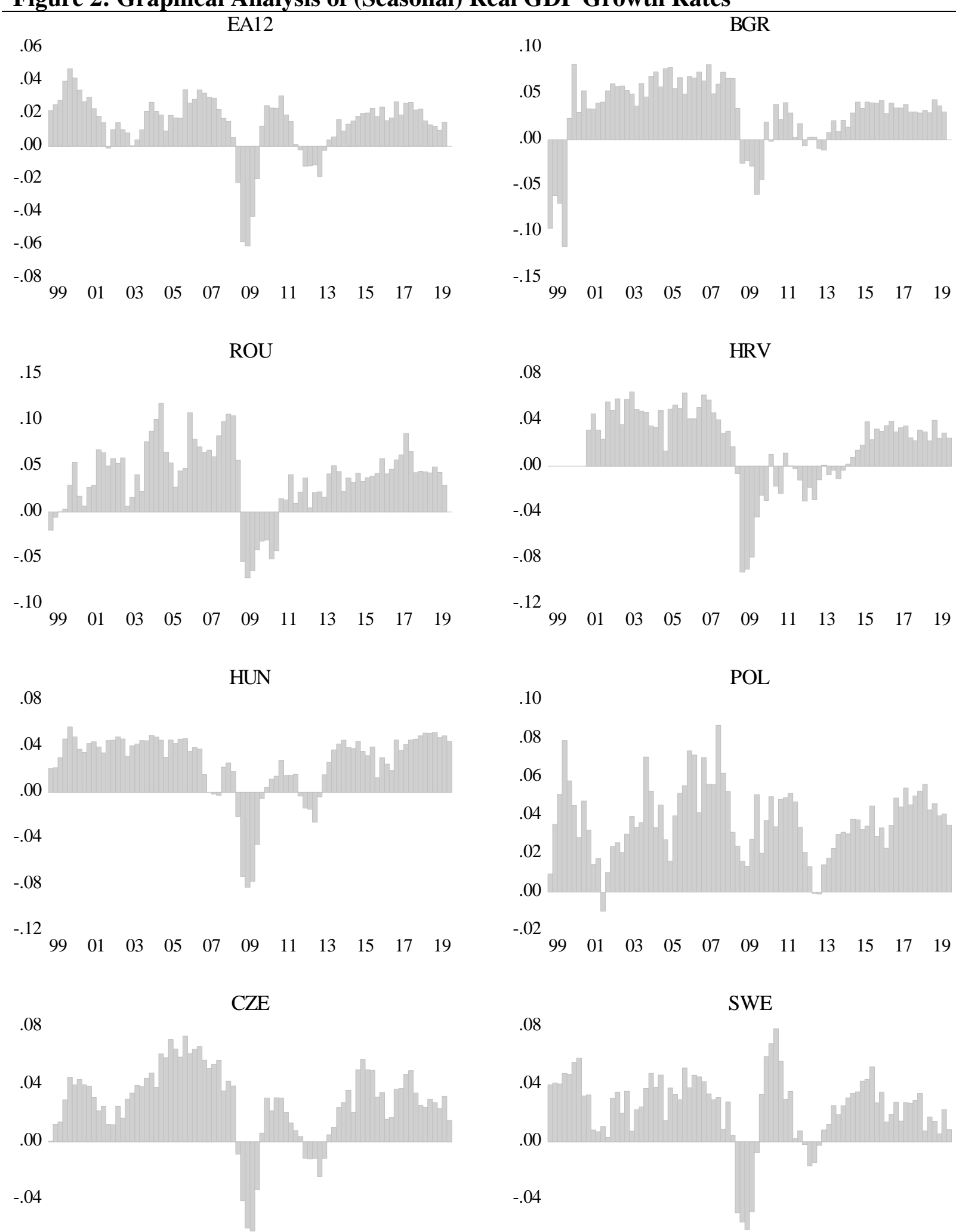

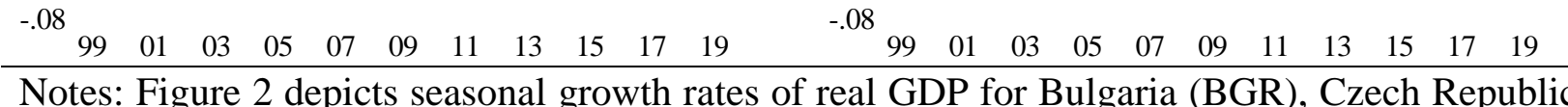
(CZE), Croatia (HRV), Hungary (HUN), Poland (POL), Romania (ROU), Sweden (SWE), the 12 founding euro area members (EA12), consisting of Austria, Belgium, Finland, France, Germany, Greece, Ireland, Italy, Luxembourg, the Netherlands, Portugal and Spain, and the recent members of the euro area (EA19), additionally including Cyprus, Estonia, Latvia, Lithuania, Malta, Slovakia, and Slovenia, 


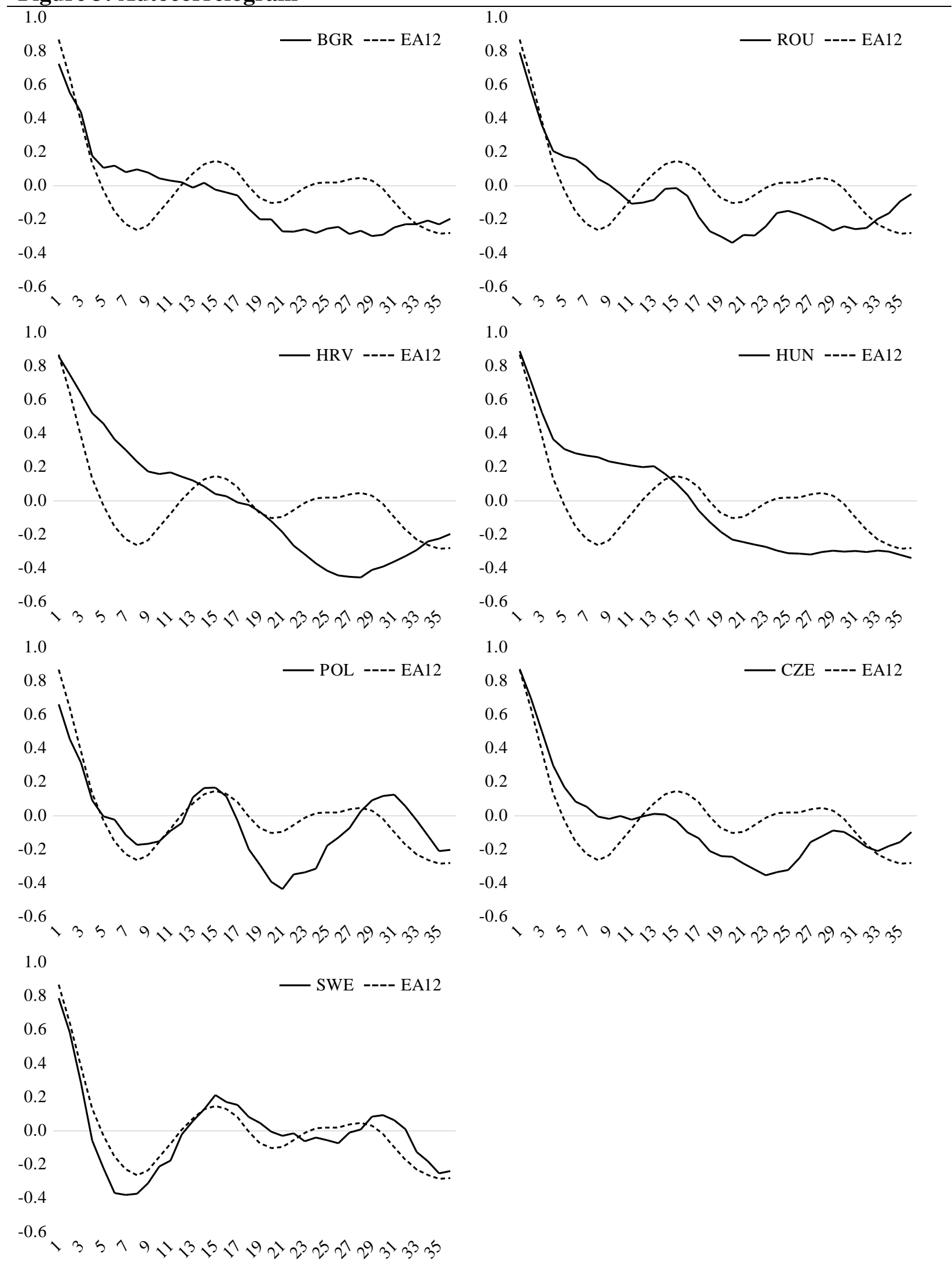

Notes: Figure 3 shows estimated sample autocorrelation functions of real GDP growth rates (seasonal differences of logged values) over 36 quarters. 
Table 2: HEGY-Seasonal Unit Root Tests for log-levels (seasonally unadjusted)

\begin{tabular}{lllll}
\hline & \multicolumn{3}{c}{ Frequency } \\
\cline { 2 - 5 } Country & 0 & PI & PI/2 & All seasonal frequencies \\
\hline EA12 & -2.455 & -2.179 & $14.803^{* * *}$ & $12.010^{* * *}$ \\
BGR & -1.919 & $-2.537^{*}$ & 3.240 & 4.910 \\
ROU & -1.996 & -1.747 & $7.308^{* *}$ & $6.173^{* *}$ \\
HRV & -2.305 & -1.878 & 1.250 & 2.004 \\
HUN & -1.699 & $-2.653^{*}$ & $13.402^{* * *}$ & $12.517^{* * *}$ \\
POL & -2.403 & $-2.658^{*}$ & $11.690^{* * *}$ & $10.321^{* * *}$ \\
CZE & -2.202 & $-3.890^{* * *}$ & $10.252^{* * *}$ & $11.714^{* * *}$ \\
SWE & $-3.286^{*}$ & $-2.939^{* *}$ & $14.022^{* * *}$ & $11.974^{* * *}$
\end{tabular}

Note: Regressors include, intercept, trend, and seasonal dummies. Optimal lag order between 1 and 7 is derived from the Akaike Information Criterion

Table 3: Seasonal Cointegration Tests for log-levels (unadjusted) with trend / Bivariate against EA-12

\begin{tabular}{llllll}
\hline & & \multicolumn{3}{c}{$\mathbf{0}$} & \multicolumn{2}{c}{$\boldsymbol{r}$} \\
& Lags & $\mathrm{r}=0$ & $\mathrm{r} \leq 1$ & $\mathrm{r}=0$ & $\mathrm{r} \leq 1$ \\
\cline { 2 - 6 } BGR & 7 & $23.073^{* * *}$ & 0.217 & $16.342^{* * *}$ & 6.761 \\
ROU & 5 & 8.485 & 0.532 & $7.793^{*}$ & 3.103 \\
HRV & 6 & $18.462^{* * *}$ & 2.112 & $8.017^{*}$ & 2.320 \\
HUN & 6 & $11.625^{*}$ & 0.251 & 6.119 & 0.568 \\
POL & 5 & $21.180^{* * *}$ & 0.022 & $15.258^{* * *}$ & 0.754 \\
CZE & 5 & 7.885 & 0.000 & - & - \\
SWE & 7 & $14.640^{* *}$ & 3.334 & - & - \\
\hline
\end{tabular}

Notes: Trace Statistics. *,**,** indicates the rejection of the null based on linearly interpolated critical values of Lee and Siklos (1995). Optimal lag order between 1 and 7 is derived by Akaike Information Criterion of the bivariate VAR incl. deterministic trends and seasonal dummies. 
Table 4: Optimal GMM Test

\begin{tabular}{|c|c|c|c|c|c|c|c|c|c|c|c|}
\hline & \multirow{3}{*}{$\begin{array}{l}\text { Cointegration } \\
\text { at Frequency }\end{array}$} & & \multicolumn{9}{|c|}{ Codependence of order } \\
\hline & & & & $\mathbf{0}$ & & 1 & & 2 & & 3 & \\
\hline & & Lags & Null & Stat. & Prob. & Stat. & Prob. & Stat. & Prob. & Stat. & Prob. \\
\hline \multirow{2}{*}{ BGR } & \multirow{2}{*}{$0, \pi$} & \multirow{2}{*}{7} & GMM & 46.26 & 0.000 & 39.02 & 0.001 & 32.24 & 0.006 & 24.79 & 0.053 \\
\hline & & & 2SLS & & & 28.59 & 0.018 & 26.41 & 0.034 & 13.07 & 0.597 \\
\hline \multirow{2}{*}{ ROU } & \multirow{2}{*}{ - } & \multirow{2}{*}{5} & GMM & 72.60 & 0.000 & 56.05 & 0.000 & 44.22 & 0.000 & 32.63 & 0.000 \\
\hline & & & 2SLS & & & 34.80 & 0.000 & 33.56 & 0.000 & 12.63 & 0.180 \\
\hline \multirow{2}{*}{ HRV } & \multirow{2}{*}{$\mathbf{0}$} & \multirow{2}{*}{6} & GMM & 31.70 & 0.002 & 27.26 & 0.007 & 24.67 & 0.016 & 19.12 & 0.086 \\
\hline & & & 2SLS & & & 18.75 & 0.095 & 16.59 & 0.166 & 9.94 & 0.621 \\
\hline \multirow{2}{*}{ HUN } & \multirow{2}{*}{-} & \multirow{2}{*}{6} & GMM & 43.42 & 0.000 & 34.26 & 0.000 & 28.20 & 0.003 & 16.08 & 0.138 \\
\hline & & & 2SLS & & & 21.14 & 0.032 & 19.93 & 0.046 & 7.73 & 0.737 \\
\hline \multirow{2}{*}{ POL } & \multirow{2}{*}{$0, \pi$} & \multirow{2}{*}{5} & GMM & 77.16 & 0.000 & 62.86 & 0.000 & 45.12 & 0.000 & 28.88 & 0.002 \\
\hline & & & 2SLS & & & 42.15 & 0.000 & 39.28 & 0.000 & 11.66 & 0.390 \\
\hline \multirow{2}{*}{ CZE } & \multirow{2}{*}{ - } & \multirow{2}{*}{5} & GMM & 19.35 & 0.022 & 10.41 & 0.319 & 5.92 & 0.747 & 4.75 & 0.855 \\
\hline & & & 2SLS & & & 7.61 & 0.574 & 7.60 & 0.575 & 2.70 & 0.975 \\
\hline \multirow{2}{*}{ SWE } & \multirow{2}{*}{ 0 } & \multirow{2}{*}{7} & GMM & 17.24 & 0.244 & 12.85 & 0.538 & 9.82 & 0.775 & 10.11 & 0.754 \\
\hline & & & 2SLS & & & 9.75 & 0.780 & 7.60 & 0.909 & 7.77 & 0.901 \\
\hline
\end{tabular}

Notes: Optimal GMM/2SLS $\chi 2$ test statistics and relative p-values. Lag order selection, see Table 3. 
Table 5: Sensitivity to Lag Choice

\begin{tabular}{|c|c|c|c|c|c|c|c|c|c|c|c|}
\hline & \multirow{3}{*}{$\begin{array}{l}\text { Cointegration } \\
\text { at Frequency }\end{array}$} & \multirow[b]{3}{*}{ Lags } & \multicolumn{9}{|c|}{ Codependence of order } \\
\hline & & & & $\mathbf{0}$ & & 1 & & 2 & & 3 & \\
\hline & & & Null & Stat. & Prob. & Stat. & Prob. & Stat. & Prob. & Stat. & Prob. \\
\hline \multirow{4}{*}{ BGR } & \multirow{2}{*}{$0, \pi$} & \multirow{2}{*}{6} & GMM & 47.21 & 0.000 & 35.16 & 0.001 & 32.28 & 0.002 & 21.92 & 0.057 \\
\hline & & & 2SLS & & & 26.53 & 0.014 & 23.16 & 0.040 & 12.84 & 0.461 \\
\hline & \multirow{2}{*}{$0, \pi$} & \multirow{2}{*}{8} & GMM & 45.98 & 0.000 & 38.32 & 0.002 & 31.74 & 0.016 & 26.98 & 0.058 \\
\hline & & & 2SLS & & & 28.85 & 0.036 & 26.83 & 0.061 & 13.92 & 0.673 \\
\hline \multirow{4}{*}{ ROU } & \multirow{2}{*}{$\pi$} & \multirow{2}{*}{4} & GMM & 77.31 & 0.000 & 58.56 & 0.000 & 45.49 & 0.000 & 31.58 & 0.000 \\
\hline & & & 2SLS & & & 36.98 & 0.000 & 32.35 & 0.000 & 12.71 & 0.122 \\
\hline & \multirow{2}{*}{$\pi$} & \multirow{2}{*}{6} & GMM & 69.74 & 0.000 & 55.73 & 0.000 & 45.48 & 0.000 & 31.66 & 0.002 \\
\hline & & & 2SLS & & & 34.95 & 0.000 & 33.70 & 0.001 & 13.33 & 0.345 \\
\hline \multirow{4}{*}{ HRV } & \multirow{2}{*}{0} & \multirow{2}{*}{5} & GMM & 31.46 & 0.000 & 24.88 & 0.006 & 21.01 & 0.021 & 18.51 & 0.047 \\
\hline & & & 2SLS & & & 15.95 & 0.101 & 16.67 & 0.082 & 10.12 & 0.430 \\
\hline & \multirow{2}{*}{$0, \pi$} & \multirow{2}{*}{7} & GMM & 32.71 & 0.005 & 28.28 & 0.020 & 24.47 & 0.058 & 18.06 & 0.260 \\
\hline & & & 2SLS & & & 20.02 & 0.171 & 19.07 & 0.211 & 8.97 & 0.879 \\
\hline \multirow{4}{*}{ HUN } & \multirow{2}{*}{-} & \multirow{2}{*}{5} & GMM & 42.75 & 0.000 & 33.33 & 0.000 & 26.38 & 0.002 & 17.09 & 0.047 \\
\hline & & & 2SLS & & & 21.65 & 0.010 & 20.44 & 0.015 & 8.74 & 0.461 \\
\hline & \multirow{2}{*}{-} & \multirow{2}{*}{7} & GMM & 42.33 & 0.000 & 34.07 & 0.001 & 25.18 & 0.022 & 14.69 & 0.327 \\
\hline & & & 2SLS & & & 21.23 & 0.069 & 17.64 & 0.172 & 7.32 & 0.885 \\
\hline \multirow{4}{*}{ POL } & \multirow{2}{*}{$0, \pi$} & \multirow{2}{*}{4} & GMM & 74.44 & 0.000 & 67.22 & 0.000 & 47.56 & 0.000 & 30.29 & 0.000 \\
\hline & & & 2SLS & & & 45.40 & 0.000 & 41.23 & 0.000 & 12.89 & 0.168 \\
\hline & \multirow{2}{*}{$0, \pi$} & 6 & GMM & 72.04 & 0.000 & 59.98 & 0.000 & 40.98 & 0.000 & 28.88 & 0.007 \\
\hline & & & 2SLS & & & 42.75 & 0.000 & 39.03 & 0.000 & 13.96 & 0.376 \\
\hline & 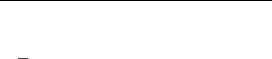 & 4 & GMM & 20.06 & 0.005 & 10.11 & 0.183 & 5.40 & 0.611 & 4.18 & 0.759 \\
\hline CZE & - & 4 & 2SLS & & & 7.02 & 0.427 & 6.67 & 0.464 & 2.61 & 0.918 \\
\hline & - & 6 & GMM & 18.64 & 0.068 & 10.40 & 0.495 & 6.20 & 0.859 & 4.99 & 0.932 \\
\hline & - & 6 & 2SLS & & & 7.54 & 0.754 & 8.00 & 0.713 & 3.04 & 0.990 \\
\hline & - & 6 & GMM & 19.48 & 0.053 & 13.13 & 0.285 & 9.54 & 0.572 & 6.36 & 0.849 \\
\hline SWE & - & 0 & 2SLS & & & 9.36 & 0.588 & 6.75 & 0.819 & 5.61 & 0.898 \\
\hline SVVE & 0 & 8 & GMM & 16.64 & 0.410 & 12.80 & 0.687 & 12.34 & 0.720 & 12.42 & 0.714 \\
\hline & 0 & 8 & 2SLS & & & 10.09 & 0.862 & 9.44 & 0.894 & 9.30 & 0.901 \\
\hline
\end{tabular}

Notes: Optimal GMM/2SLS $\chi 2$-tests including $\mathrm{p}-1$ or $\mathrm{p}+1$ lags, with $\mathrm{p}$ being the lag order of the benchmark specification reported in Table 4. 
Table 6: Tiao and Tsay (1989) Codependence Test

\begin{tabular}{|c|c|c|c|c|c|c|c|c|c|c|c|}
\hline & \multirow{3}{*}{$\begin{array}{l}\text { Cointegration } \\
\text { at Frequency }\end{array}$} & \multirow[t]{3}{*}{ Lags } & \multirow[t]{3}{*}{ Null } & \multicolumn{7}{|c|}{ Codependence of order } & \\
\hline & & & & $\mathbf{0}$ & & 1 & & 2 & & 3 & \\
\hline & & & & Stat. & Prob. & Stat. & Prob. & Stat. & Prob. & Stat. & Prob. \\
\hline \multirow{2}{*}{ BGR } & \multirow{2}{*}{$0, \pi$} & \multirow{2}{*}{7} & $k=1$ & 103.83 & 0.000 & 25.03 & 0.050 & 15.54 & 0.413 & 7.23 & 0.951 \\
\hline & & & $\mathbf{k}=\mathbf{2}$ & 261.64 & 0.000 & 55.50 & 0.006 & 35.35 & 0.313 & 23.37 & 0.866 \\
\hline \multirow{2}{*}{ ROU } & & \multirow{2}{*}{5} & $k=1$ & 98.02 & 0.000 & 22.34 & 0.008 & 10.40 & 0.319 & 7.37 & 0.598 \\
\hline & & & $\mathbf{k}=\mathbf{2}$ & 233.32 & 0.000 & 46.76 & 0.001 & 25.75 & 0.174 & 18.18 & 0.576 \\
\hline \multirow{2}{*}{ HRV } & \multirow{2}{*}{$\mathbf{0}$} & \multirow{2}{*}{6} & $\mathbf{k}=\mathbf{1}$ & 86.83 & 0.000 & 22.77 & 0.030 & 11.77 & 0.464 & 5.27 & 0.948 \\
\hline & & & $\mathbf{k}=\mathbf{2}$ & 224.71 & 0.000 & 48.58 & 0.005 & 29.46 & 0.291 & 19.66 & 0.807 \\
\hline \multirow{2}{*}{ HUN } & & \multirow{2}{*}{6} & $k=1$ & 109.03 & 0.000 & 21.96 & 0.025 & 11.56 & 0.398 & 5.17 & 0.923 \\
\hline & & & $k=2$ & 271.91 & 0.000 & 49.44 & 0.002 & 29.36 & 0.207 & 18.70 & 0.768 \\
\hline \multirow{2}{*}{ POL } & \multirow{2}{*}{$0, \pi$} & \multirow{2}{*}{5} & $k=1$ & 81.76 & 0.000 & 25.32 & 0.008 & 13.41 & 0.267 & 5.59 & 0.899 \\
\hline & & & $k=2$ & 222.88 & 0.000 & 53.64 & 0.000 & 39.32 & 0.025 & 26.10 & 0.348 \\
\hline \multirow{2}{*}{ CZE } & \multirow[b]{2}{*}{-} & \multirow{2}{*}{5} & $k=1$ & 74.31 & 0.000 & 16.64 & 0.055 & 8.34 & 0.501 & 4.07 & 0.907 \\
\hline & & & $k=2$ & 211.36 & 0.000 & 39.31 & 0.006 & 20.52 & 0.426 & 10.38 & 0.961 \\
\hline \multirow{2}{*}{ SWE } & \multirow{2}{*}{$\mathbf{0}$} & \multirow{2}{*}{7} & $k=1$ & 74.98 & 0.000 & 23.60 & 0.051 & 10.58 & 0.719 & 5.76 & 0.972 \\
\hline & & & $k=2$ & 217.92 & 0.000 & 55.07 & 0.003 & 34.64 & 0.256 & 26.65 & 0.641 \\
\hline
\end{tabular}

Notes: Tiao and Tsay (1989) test statistics and relative p-values. Lag order selection, see Table 3. 


\section{Appendix}

Figure 1: Half-life estimates [quarters]

12

10

8

6

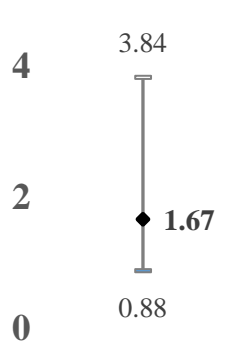

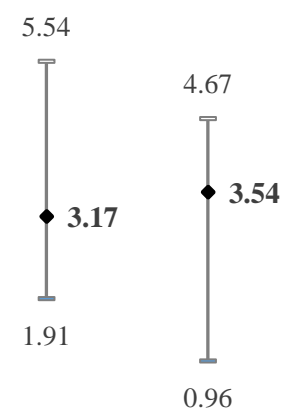
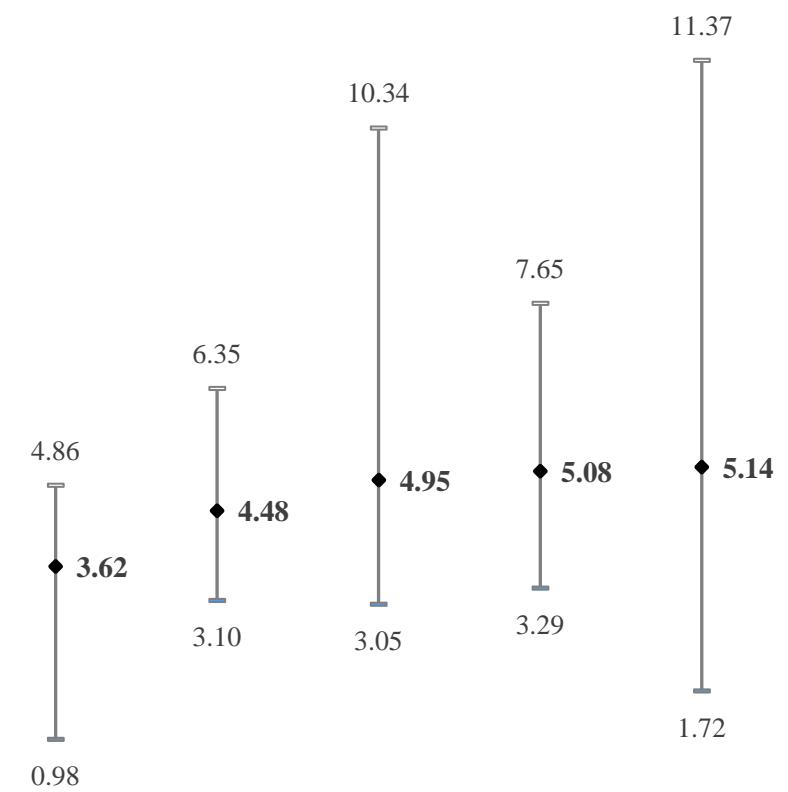

POL ROU SWE

BGR

EA12

HUN

CZE HRV

Notes: Figure 1 depicts half-life estimates (+/- 2 standard errors) based on the impulse response of a vector autoregressive model with 4 lags.

Table 1: Correlation Coefficients

\begin{tabular}{llllllll}
\hline & BGR & ROU & HRV & HUN & POL & CZE & SWE \\
\hline \multirow{2}{*}{ EA12 } & $0.307^{* * *}$ & $0.442^{* * *}$ & $0.730^{* * *}$ & $0.760^{* * *}$ & $0.515^{* * *}$ & $0.810^{* * *}$ & $0.880^{* * *}$ \\
& {$[2.90]$} & {$[4.43]$} & {$[9.13]$} & {$[10.54]$} & {$[5.41]$} & {$[12.44]$} & {$[16.65]$} \\
\hline
\end{tabular}

Notes: Table reports (Pearson) correlation coefficients between countries' real GDP growth rates (seasonal differences). t-statistics for the null of the coefficient being unequal to zero are given in parenthesis. ${ }^{*}, * *, * * *$ indicate statistical significance at $10 \%, 5 \%$, and 1\% level, respectively. The sample period is 1999Q1-2019Q3. 